\title{
Added Value of Power Control in Improving the Integration of Wind Turbines in Weak Grid Conditions
}

\author{
Abdelaziz Arbaoui ${ }^{1}$, Mohamed Asbik ${ }^{2}$, Khalid Loudiyi ${ }^{3}$, Khalid Benhamou $^{4}$ \\ ${ }^{1}$ ENSAM, Meknès Ismaïlia, Morocco \\ ${ }^{2}$ Laboratoire de Physique des Matériaux et Modélisation des Systèmes (LP2MS), Unité associée au \\ CNRST-URAC: 08, Faculté des Sciences, Meknès, Maroc \\ ${ }^{3}$ Al Akhawayn University, Ifrane, Morocco \\ ${ }^{4}$ Sahara Wind Inc., Rabat, Morocco \\ E-mail:asbik_m@yahoo.fr \\ Received May 13, 2010; revised July 7, 2010; accepted August 15, 2010
}

\begin{abstract}
For economical reasons, wind turbine systems must be located in favourable sites generating a higher productivity. These are often located in areas with weak electric grid infrastructures. The constraints related to this type of grids limit the penetration levels of wind energy. These constraints are mainly related to power quality in the grid as well as the economical aspects of the project. In this study, we take into account the slow voltage variations and the flicker phenomenon. The models used are based on the development of a set of relations derived from engineering knowledge related to both technical and economical points of view. The maximal penetration level of a fixed speed wind turbine system is determined for a given grid. The power control has been investigated to improve wind turbine system integration. Obtained results show the necessity to adapt technological choices to the requirements of weaker grids. Penetration levels and wind turbine cost may be greatly improved using variable speed systems.
\end{abstract}

Keywords: Wind Turbine, Power Quality, Power Control, Weak Grid, Cost Modeling

\section{Introduction}

The current institutional and technical evolutions in the field of electrical energy production schemes involve a substantial growth of distributed generation using wind turbine systems. Because of renewable and carbon-free characteristics (cleanliness) of the energy produced, incorporating such systems has become a key element in the new energy policies of many countries. Governments and non-trading companies have shown an important interest in achieving what can be considered as sustainable development objectives through the extensive incorporation of wind energy into electricity generation systems. Electricity distributors are interested in the viability and lower costs as well as the quality of the energy produced. Aims of investors have been focalized on potential profits whereas designers, manufacturers and project managers define the architecture of the system and its suitability to the sites.

For economical reasons the wind turbine systems must be implanted in more favourable windier sites which are often located in areas with weak electric grid infrastructures. The constraints related to this type of grids limit the penetration levels of wind energy. These constraints are mainly those related to power quality in the connection node and to the economical aspects of the project.

The concept of power quality is related to the level of satisfaction of the costumers, so the constraints related to grid connection are imposed by the loads connected to it. These constraints are described by norms that specify the tolerances levels which must be guaranteed for the voltage as well as for the others disturbances usually met within the grid. From a technical point of view, the power quality constraints related to the weak grid that may limit the penetration of wind energy depends on the characteristics of both the wind turbine and the grid, they are mainly $[1,2]$ :

- Voltage variations: slow variations and fast variations known as flickers

- Harmonics and interharmonics,

- Stability and thermal capacity problems.

Several solutions exist to increase the penetration of the wind energy production. These solutions use different 
technologies and concepts, and include the following:

- Grid reinforcement by installation of new lines;

- Control of reactive power;

- Introduction of load management;

- Dissipation of wind energy;

- Application of energy storage;

Each solution generates additional costs which can impact the project's profitability. As an example for grid reinforcements, a line of $10 \mathrm{kV}, 100 \mathrm{~mm} 2 \mathrm{Al}$ PEX costs 30.000 \$USA per miles [3].

In this paper we will take into account the slow voltage variations and the flicker phenomenon constraints. The objective is to study the value added of reactive power control in improving the integration of wind turbines in weak grid conditions. To reach this goal, the used models are based on the development of a set of relations derived from engineering knowledge related to both technical and economical points of view. The technical knowledge base describes the models of the grid and the wind turbine, the interaction between them, and the power quality constraints. The economical knowledge base is related to the electric energy production, project investment and wind turbine components costs. All models are developed as a Constraint Satisfaction Problem (CSP) which is then implemented on a digital CSP solver based on interval analysis to be solved [4].

\section{Technical Knowledge Base}

\subsection{Weak Grid Model and Voltage Variations Constraints}

Various approaches are used to calculate the voltage variation caused by the connection of a wind system: determinist, temporal and probabilistic [5]. In this study we use the first approach; the grid model used is represented in Figure 1. $U_{1}$ is the voltage of infinite bus, $U_{2}$ the voltage at the point of common coupling (PCC), and $Z$ is the equivalent impedance of the grid at this point.

The short-circuit power of the grid is given by:

$$
S_{S c}=\frac{U_{1}^{2}}{Z}=\frac{U_{1}^{2}}{\sqrt{R^{2}+X^{2}}}
$$

When the voltage is constant, the short-circuit power is constant if the impedance of the grid is constant. It should nevertheless be specified that a given value of $S_{S c}$ can be obtained for various values of the ratio $X / R$. This ratio varies according to the level of the voltage, the configu-

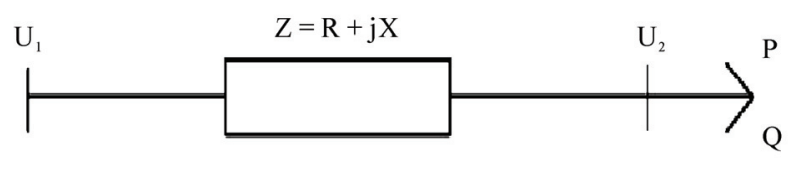

Figure 1. Grid model.

ration of the grid, type of lines and their geometries.

The voltage variations are caused by variation of the active power and the reactive power flow; the voltage at the PPC can be expressed as Equation (2) [6]:

The authorized maximum voltage variation is defined by the international commission of electrical engineering (IEC 868). In Figure 2, the upper curve shows the maximum permissible voltage variation with respect to the frequency of the fluctuation [1]. For safety reasons, the acceptable voltage variations defined by the lower curve of the Figure 2 is adopted in this model.

Part (1) of the curve specifies that the slow voltage variations are acceptable if they are lower than $3 \%$ of the nominal voltage in the grid. For safety reasons we suppose that the slow voltage variations are acceptable if they are lower than $2.5 \%$ of the nominal voltage in grid.

$$
\Delta U(\%)=100\left|\frac{U_{1}-U_{2}}{U_{1}}\right| \leq 2.5
$$

Part (2) of the curve shows the acceptable limit of the flicker phenomenon. This limit can be translated, according to the frequency $\mathrm{F}$, by the following constraint:

$$
\Delta U(\%)=100\left|\frac{U_{1}-U_{2}}{U_{1}}\right| \leq 0.628 F^{-0.3}
$$

Commonly, a point of the grid is considered weak if it is poorly interconnected, far from the principal conventional production units or if it is isolated. A current practice of the electrical engineers, is to evaluate the weakness of a point of the grid by using the short-circuit power. The value of this important parameter is provided by the distributor; it depends on the number and the characteristics of the generation units feeding the grid as well as of the equivalent impedance (lines and transformers impedances) starting from the conventional production units up to the point of study. According to the value of the short-circuit power, the grid is considered weak or strong. The weaker the grid is, the more it is affected by the disturbances which come from the new built-in elements (loads or distributed production systems). When the short-circuit power is sufficiently high, it is considered that the quality of electrical energy in the grid is not affected by new

$$
U_{2}=\sqrt{\frac{U_{1}^{2}}{2}-(R P+X Q)+\sqrt{\left[\frac{U_{1}^{2}}{2}-(R P+X Q)\right]^{2}-\left(P^{2}+Q^{2}\right)\left(R^{2}+X^{2}\right)}}
$$




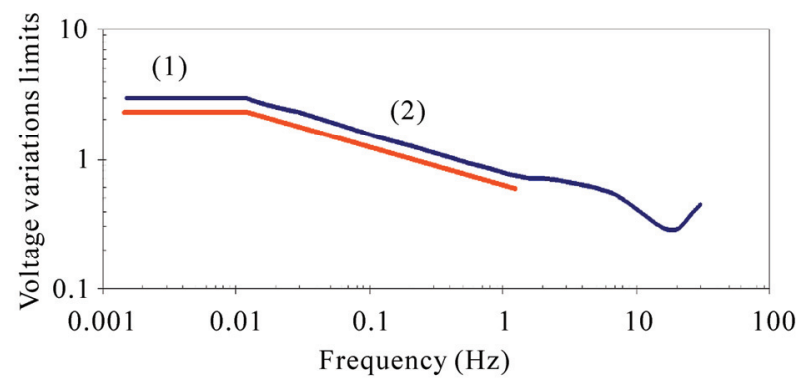

Figure 2. Maximum voltage variation authorized according to IEC 868.

installations. In this case, we can say that the grid is strong at this point.

The short-circuit power only characterizes the weakness of the PPC from the grid point of view. To take into account the wind turbine system, we generally use the short-circuit ratio $S_{C r}$. This criterion is very important during the development of the scenarios of energy supply by a wind turbine in a given region. Although, the precise study of each particular case leads to various suitable minimal values for the $S_{C r}$, it is considered that the grid is prone to be weak if $S_{C r}<20$ [7].

$$
S_{C r}=\frac{S_{S c}}{P_{n}}
$$

\subsection{Active Power Flow}

Within the general category of horizontal axis wind turbines for grid applications there exists a variety of possible power control strategies. In this study, the following design variables are chosen to define a horizontal axis wind turbine:

- the nominal power, $P_{n}$

- the rotor diameter, $D$

- the rotational speed, $N$

- the design speed, $V_{\text {des }}$

- the number of blades, $p$

- Control type: constant-speed stall (CSS), constant-speed pitch (CSP), and variable-speed pitch (VSP).

All of these design variables are often given in manufacturers catalogues.

The power production of a wind turbine is:

$$
P=\frac{1}{2} \rho \cdot C_{e} \cdot A \cdot V^{3}
$$

The efficiency factor depends on both wind speed and system architecture [8]:

$$
C_{e}(V)=C_{e m} \cdot \exp \left[-\frac{\left(\ln V-\ln V_{d e s}\right)^{2}}{2(\ln s)^{2}}\right]
$$

In this expression, the system is characterised by its maximum efficiency $C_{e m}$, its optimum operating speed $V_{\text {des }}$ (design speed), and its operating range $s$. The nominal power of the wind turbine is given by:

$$
P_{n}=\frac{1}{2} \rho \cdot C_{e m} \cdot A \cdot V_{d e s} \cdot \exp \left(\frac{9}{2}(\ln s)^{2}\right)
$$

$C_{e m}$ is calculated from the performance of the power conversion unit:

$$
C_{e m}=C_{p \max } \cdot \eta_{m} \cdot \eta_{g}
$$

The maximum value of $C_{p}$ is calculated using an analytical relationship [9]:

$$
C_{P \max }=0.593 \cdot\left[\begin{array}{l}
\frac{\lambda_{\max } p^{0.67}}{1.48+\left(p^{0.67}-0.04\right) \lambda_{\max }+0.0025 \lambda_{\max }^{2}} \\
-\frac{1.92 \lambda_{\max }^{2} p}{1+2 \lambda_{\max } p} \cdot \frac{C_{x}}{C_{z}}
\end{array}\right]
$$

where $\lambda_{\max }=\frac{\pi N D}{60 V_{d e s}}$

The efficiency of the gearbox is given by [10]:

$$
\eta_{m}=1-\left[\left(1-\pi_{m}\right)\left(\frac{P_{n}}{P}+3\right) / 4\right]
$$

with $\pi_{m}=0.89 P_{n}^{0.012}$

The efficiency of the generator is given by [10]:

$$
\eta_{g}=1-\left[\left(1-\pi_{g}\right)\left(5\left(\frac{P \eta_{m}}{P_{n g}}\right)^{2}+1\right)\left(\frac{P_{n g}}{6 \eta_{m} P}\right)\right]
$$

with $\pi_{g}=0.87 P_{n}^{0.014}$

and $P_{n g}=P_{n} \pi_{m} \pi_{g} F_{s}$

In this last expression, $F_{s}$ represent the service factor of the gearbox, which is defined by the following logical constraint [10]:

$$
\left\{\begin{array}{l}
\text { Control.type }=C S S \rightarrow F_{s}=2 \\
\text { Control.type }=C S P \rightarrow F_{s}=1,75 \\
\text { Control.type }=V S P \rightarrow F_{s}=1,25
\end{array}\right.
$$

The model above is used to calculate the power production of a $600 \mathrm{~kW}$ wind turbine, whose result is shown in Figure 3.

\subsection{Reactive Power Flow}

At this stage of problem definition, we need to perform a relationship between the active and the reactive power of a wind turbine. To achieve this target, we use the equi- 


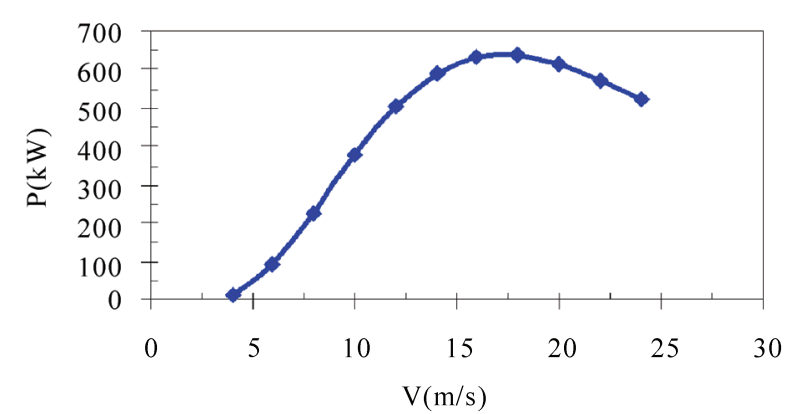

Figure 3. Active power of a $600 \mathrm{~kW}$ wind turbine.

valent circuit of the induction generator represented in Figure 4, $R_{s}$ and $R_{r}$ are respectively resistance of the rotor and of the stator, $X_{s}$ and $X_{r}$ are their reactance, $X_{m}$ is the magnetizing reactance. The induction generator is considered saturated and we admit the existence of a reactance $j X_{c}$ which corresponds to the compensating capacitors [11].

The reactive power consumption of the induction generator is given by:

$$
\begin{aligned}
& Q=V_{o}^{2} \frac{X_{C}-X_{m}}{X_{C} X_{m}}+X_{g} \frac{V_{o}^{2}+2 R_{g} P_{m}}{2\left(R_{g}{ }^{2}+X_{g}{ }^{2}\right)} \\
& -X_{g} \frac{\sqrt{\left(V_{o}^{2}+2 R_{g} P_{m}\right)^{2}-4 P_{m}^{2}\left(R_{g}{ }^{2}+X_{g}{ }^{2}\right)}}{2\left(R_{g}{ }^{2}+X_{g}{ }^{2}\right)}
\end{aligned}
$$

With: $R_{g}=R_{s}+R_{r}$ and $X_{g}=X_{s}+X_{r}$.

The input parameters in the last equation are the characteristics of the induction generator and the power at the output of the gearbox $P_{m}$ which can be calculated by:

$$
P_{m}=P / \eta_{g}
$$

Figure 5 shows the reactive consumption of a $600 \mathrm{~kW}$ wind turbine calculated by the performed relationship:

To take into account the flicker phenomenon, we suppose that the wind turbine power fluctuations are caused by the tower shadow and that their amplitude is $20 \%$ of the nominal power of the wind turbine [6]. At the same time we consider that the frequency of these fluctuations as being 2 or 3 times the rotational frequency according to the number of blades:

$$
F=\frac{p N}{60}
$$

\section{Economical Knowledge Base}

From the economical point of view, the need consists in being able to characterize the impact of power control on performance and cost of the wind turbine. We use the quality index, which is the ratio of the electricity produced

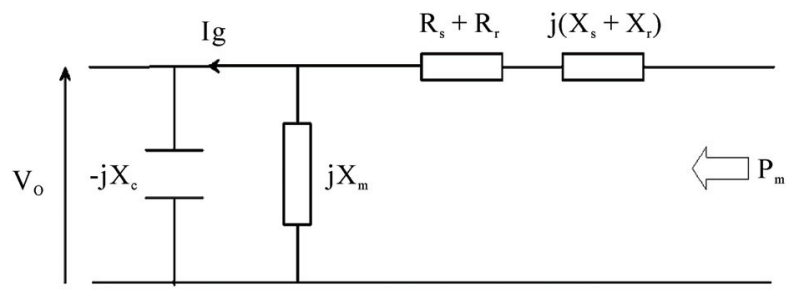

Figure 4. Equivalent circuit of induction generator.

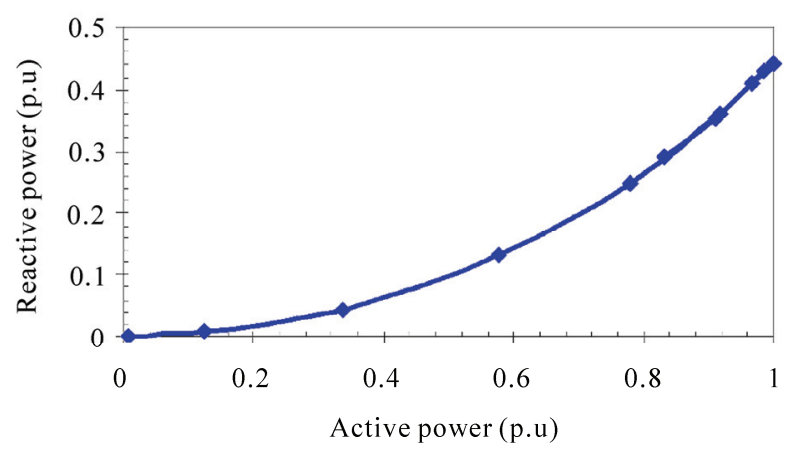

Figure 5. Reactive power consumption of a $600 \mathrm{~kW}$ wind turbine.

over the total cost of the wind turbine, to study this impact.

$$
Q I=\frac{E}{C_{W T}}
$$

To evaluate the quality index we use the models described in the following paragraphs.

\subsection{Annual Electricity Produced}

The annual electricity output $\left(E_{a p}\right.$ in $\mathrm{kWh} / \mathrm{year}$ of the wind turbine having a rotor with a surface area $\mathrm{A}$ and the start/stop wind speeds $\left(V_{i}\right.$ and $\left.V_{f}\right)$, is the sum of the energies produced in one year ( 8,760 hours) reduced by the efficiency factor of the system:

$$
E_{a p}=\frac{8.760 \cdot \rho}{2} \cdot A \cdot \sum_{V_{i}}^{V_{f}} f(V) \cdot C_{e}(V) \cdot V^{3} \cdot \Delta V
$$

In this equation, the wind is defined as the following Weibull distribution:

$$
f(V)=\left(\frac{k}{V}\right) \cdot\left(\frac{V}{c}\right)^{k} e^{\left(-\frac{V}{c}\right)^{k}}
$$

Scale parameter $c$ characterizes wind average speed, whereas shape parameter $k$ characterizes wind distribution which varies with height [12]:

$$
k(Z)=k_{0}+0.03 H_{h u b}+0.02
$$

where $k_{0}$ is the shape parameter at wind-measurement 
height $Z_{0}$.

The vertical gradient of wind speed is considered by introducing the following power law:

$$
\frac{c}{c_{0}}=\left(\frac{H_{h u b}}{Z_{0}}\right)^{\alpha}
$$

To have a quantitative assessment of the accuracy of the estimated annual electricity described above, we refer to the study done in 1998 by the Danish Energy Agency [13]. This study is based on measured data in various sites with respecting of the IEC standards procedures and recommendations. In this reference, we founded the power curves and the annual electricity production for several standards wind turbines. To have a clear idea about the exactitude of the used model, we have compared the measured annual electricity production $\left(E_{r e f}\right)$ and that obtained by the used model for several standards machines $(E)$.

These comparisons demonstrate that the model calculations are in close agreement with a large quantity of reference measured data. The Table 1 lists, for example, the result of this comparison for NEG NTK 500/37 wind turbine. According to this result, model calculations closely fit measured annual electricity production when the average wind speed is above $4 \mathrm{~m} / \mathrm{s}$. The difference between the estimated and measured annual electricity production is less than $3 \%$. Since the sites, which are economically viable, have an average wind speed greater than $5 \mathrm{~m} / \mathrm{s}$, we can make out that the used model is quite accurate to be used.

\subsection{Wind Turbine Cost}

The cost model of wind turbine encompasses aspects related to the design and manufacture of such systems. It

Table 1. Comparison between the measured annual electricity produced by NEG NTK 500/37 wind turbine and that obtained by the used model.

\begin{tabular}{|c|c|c|c|c|c|}
\hline \multirow{3}{*}{$\begin{array}{c}\text { Average } \\
\text { wind speed } \\
\text { at hub High } \\
V_{m}(\mathrm{~m} / \mathrm{s}) \\
4\end{array}$} & \multirow{2}{*}{\multicolumn{2}{|c|}{$\begin{array}{c}\text { Weibull } \\
\text { Parameters } \\
c \quad k \\
(\mathrm{~m} / \mathrm{s})\end{array}$}} & \multirow{3}{*}{$\begin{array}{c}E \\
\text { (MWh/year) } \\
202\end{array}$} & \multirow{3}{*}{$\begin{array}{c}E_{\text {ref }} \\
\text { (MWh/year) } \\
225\end{array}$} & \multirow{3}{*}{$\begin{array}{c}\begin{array}{c}\text { Difference } \\
(\%)\end{array} \\
-10.2\end{array}$} \\
\hline & & & & & \\
\hline & 4.51 & 2 & & & \\
\hline 5 & 5.64 & 2 & 472 & 486 & -2.9 \\
\hline 6 & 6.77 & 2 & 818 & 816 & 0,25 \\
\hline 7 & 7.90 & 2 & 1193 & 1176 & 1.45 \\
\hline 8 & 9.03 & 2 & 1557 & 1532 & 1.6 \\
\hline 9 & 10.16 & 2 & 1883 & 1858 & 1.4 \\
\hline 10 & 11.28 & 2 & 2151 & 2138 & 0.6 \\
\hline
\end{tabular}

is the sum of cost models of the components of the wind turbine. A calibration factor $F_{W T}$ allows using real wind turbine costs [14].

$$
C_{W T}=F_{W T} \times \sum_{i} C_{\text {component } i}, F_{W T}=1.1
$$

The cost of some components is calculated from weight models developed using engineering estimation rules. These have been applied to the rotor, the transmission system, the nacelle, and the tower. As for the cost of the generator and associated electrical equipment, it is correlated with power rating. The models are not presented in this paper because they require a lot of parameters, but most of them can be found in reference $[10,15]$.

\section{Value Added by Power Control}

In this study, we have chosen the site characteristics given in Table 2. To obtain a good judgement of total field of the solutions, we introduced the variation domain of the design variables gathered in Table 3. In our previous studies the global model is used to define a wind turbine in adequacy with the wind in the site [16].

Figure 6 shows obtained results. These represent the limit due to both slow voltage variation and flicker phenomenon according to the $X / R$ ratio. We notice the followings:

- For the grids with a low $X / R$ ratio, the short circuit ratio is limited by the slow voltage variations.

- For the grids having a large $X / R$ ratio, the short circuit ratio is limited by the flicker phenomenon.

This is explained by the fact that, grids with low $X / R$ ratio have their active power flow causing the slow volt-

Table 2. Characteristics of the investigated site.

\begin{tabular}{cccccc}
\hline$k_{0}$ & $c_{0}$ & $\alpha$ & $Z_{0}$ & $U_{1}$ & $S_{S c}$ \\
\hline 1.2 & 8 & 0.12 & 30 & $11 \mathrm{kV}$ & $10 \mathrm{MVA}$ \\
\hline
\end{tabular}

Table 3. Design variables and their domain of variation.

\begin{tabular}{cc}
\hline Design variable & Domain of variation \\
\hline$D(\mathrm{~m})$ & {$[20,80]$ with a step of $10 \mathrm{~m}$} \\
$P n(\mathrm{~kW})$ & {$[400,2000]$ with a step of $25 \mathrm{~kW}$} \\
$V$ des $(\mathrm{m} / \mathrm{s})$ & {$[6,12]$ with a step of $2 \mathrm{~m} / \mathrm{s}$} \\
Hhub $(\mathrm{m})$ & {$[35,70]$ with a step of $10 \mathrm{~m}$} \\
$N($ tr $/ \mathrm{mn})$ & {$[15,50]$ with a step of $5 \mathrm{tr} / \mathrm{mn}$} \\
Control type & $\ll P V C »$ or $\ll$ SVC» or $« P V V »$ \\
$p$ & 2 or 3 \\
\hline
\end{tabular}




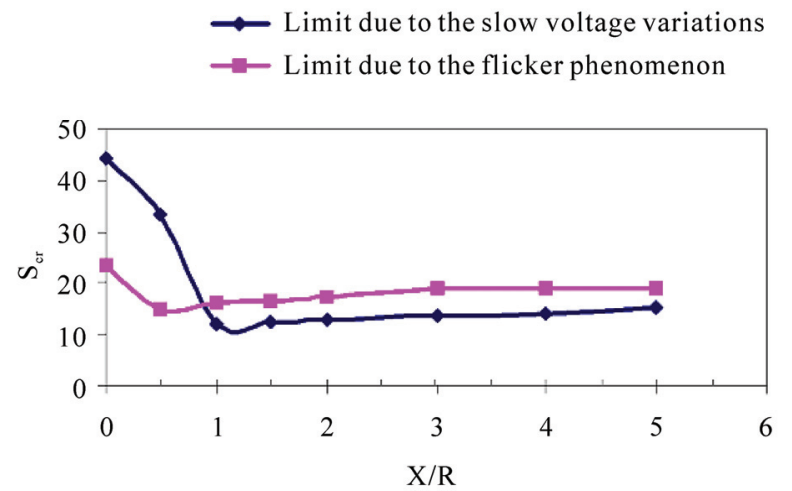

Figure 6. Minimum short-circuit ratio for the constant speed system.

age variation. However grids with high $X / R$ ratio have their reactive power flow as the main cause for the slow voltage variation [17].

For the slow variation constraint, Figure 7 represents the minimum short circuit ratio for a variable speed compared with a constant speed system. In order to highlight the importance of the reactive power control, we consider here that $\cos \phi=1$ for the variable speed system.

We point out that the reactive power control makes it possible to increase the penetration of wind energy when the $X / R$ ratio is higher than 2.7 . In the case where $X / R$ ratio lowers than 2.7 , when the rectifier is with forced commutation, it is possible to control judiciously the $\cos \phi$ in order to obtain a penetration level equal or higher than what's achieved with the constant speed system [6]. Figure 8 shows that the use of a variable speed control makes it possible to attenuate the flicker phenomenon. Contrary to the result obtained for the constant speed system, the fact of having $\cos \phi=1$ implies that the flicker phenomenon is not any more one criterion of a grid evaluation.

The results above show the positive impact of power control on the maximal penetration level which represents the technical added value of this concept. To have a good idea on this impact, for an $X / R=4$ we can install a $1425 \mathrm{~kW}$ variable speed wind turbine against only 500 $\mathrm{kW}$ if the system is a constant speed one.

The power control has also a positive impact on the quality index of the wind turbine as shown by the results obtained from the use of economical knowledge base in Table 3 and Figure 9.

The increase in the quality index is due to the reduction in the cost of the system. The annual energy produced is the same for the two concepts. In fact, the energy model used doesn't take into account the influence of the control type as Equation (17) lets us believe by introducing the service factor of the gearbox $F_{s}$. This last

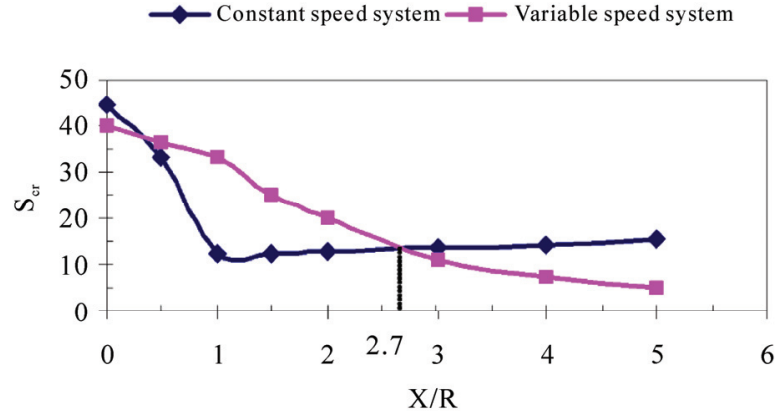

Figure 7. Minimum short-circuit ratio for slow variation constraint: Comparison between the constant and variable speed systems.

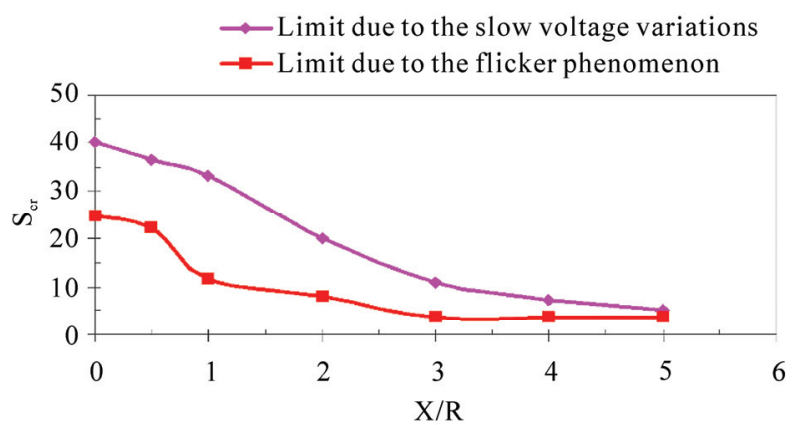

Figure 8. Minimum short-circuit ratio for variable speed system.

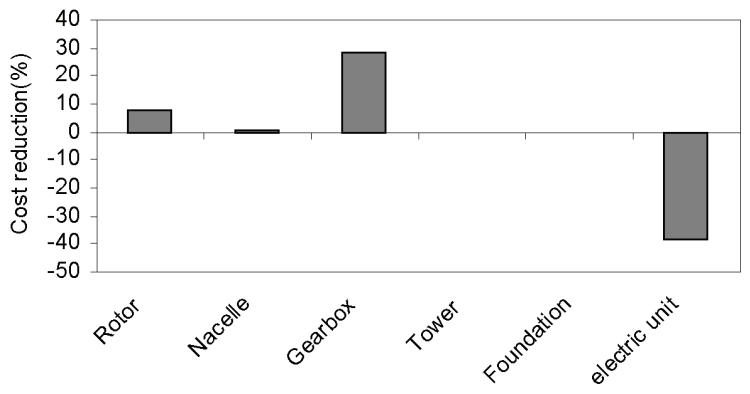

Figure 9. Cost reduction for the variable speed system.

Table 4. Criteria comparison for a $1425 \mathrm{~kW}$ wind turbine.

\begin{tabular}{cccc}
\hline \multirow{2}{*}{ Wind turbines } & \multicolumn{3}{c}{ Criteria } \\
\cline { 2 - 4 } & $I Q$ & $E$ & $C_{W T}$ \\
\hline Variable speed & 4.7 & 3.1 & 0.6 \\
Constant speed & 4.18 & 3.1 & 0.74 \\
\hline
\end{tabular}

factor has however a great influence on the components costs of wind turbine (for more details, see references $[10,15])$. By using a variable speed control a decrease in the rotor cost becomes realistic; but the greatest part of this reduction is offered by the gearbox. The gain which 
must be carried out at the level of these tow components will certainly compensates for the $40 \%$ increase in the electrical unit, while the gain at the level of the nacelle is insignificant.

\section{Conclusions}

In this work illustrates the added value of power control in improving the integration of wind turbines in weak grid conditions. We took into account wind turbines connection to the weak grid through slow voltage variations and Flicker phenomenon constraints. Ours models are based on the development of a set of relations derived from engineering knowledge related to both technical and economical points of view.

The technical knowledge base determines the maximum penetration level of fixed-speed wind turbine systems in a given grid, and evaluates the impact of reactive power control on the penetration level. The impact of reactive power control on wind turbine components costs was studied through the economical knowledge base.

All models were developed as a Constraint Satisfaction Problem (CSP) which is then implemented on a digital CSP solver based on interval analysis to be solved. Obtained results show the necessity to adapt technological choices to the requirements of weaker grids. Penetration levels and wind turbine cost may be greatly improved using variable speed systems.

For future research investigations, it would be interesting to integrate the influence of power control on the efficiency and effectiveness of a wind turbine. This may provide us a good judgement about the genuine added value of the economic point of view.

\section{References}

[1] J. O. G Tande, "Applying Power Quality Characteristics off Wind Turbines for Assessing Impact one Voltage Quality," Wind Energy, Vol. 5, No. 1, 2002, pp. 37-52.

[2] P. Bousseau, et al., "Solutions for the Grid Integration of Wind Farms-A Survey", Wind Energy, Vol. 9, No. 1, 2006, pp. 13-25.

[3] J. O. G Tande, "Exploitation of Wind-Energy Resources in Proximity to Weak Electric Grids," Applied Energy, Vol. 65, No. 1, 2000, pp. 395-401.
[4] A. Arbaoui and M. Asbik, "Constraints Based Decision Support for Site-Specific Preliminary Design of Wind Turbines," Energy and Power Engineering, Vol. 2, No. 3, 2010, pp. 161-170.

[5] N. G. Boulaxis, S. A. Papathanassiou and M. P. Papadopoulos, "Wind Turbine Effect on the Voltage Profile of Distribution Networks," Renewable Energy, Vol. 25, No. 3, 2002, pp. 401-415.

[6] A. Larson, "The Power Quality of Wind Turbines" Ph.D. Thesis for Chalmers University of Technology, Sweden, 2000.

[7] O. Alejandro, "Issues Regarding the Integration of Induction Wind Turbines in Weak Electrical Networks," Nordic Wind Power Conference, Gothenburg, 2004.

[8] C. T. Kiranoudis, N. G. Voros and Z. B. Maroulis, "Short-Cut Design of Wind Farms," Energy Policy, Vol. 29, No. 7, 2001, pp. 567-578.

[9] A. Spera, "Wind Turbine Technology," The American Society of Mechanical Engineering, 1998.

[10] R. Harrison and G. Jenkins, "Cost Modelling of Horizontal Axis Wind Turbines (Phase 2)," ETSU W/34/00170/ REP, University of Sunderland, 1994.

[11] A. E. Feijoo, "Infuencia de los Parques Eolicos en la Seguridad Estacionaria y Calidad del Onda de Redes Eléctricas de Gran Dimension," PhD Thesis of Vigo University, Vigo, 1998.

[12] I. Troen and E. L. Petersen, "European Wind Atlas," Riso National Laboratory, Roskilde, 1989.

[13] H. Petersen, "Comparison of Wind Turbines Based on Power Curve Analysis," Report Made for Danish Energy Agency's, 1998.

[14] T. Diveux, P. Sebastian, D. Bernard, J. R. Puiggali and J. Y. Grandidier, "Horizontal Axis Wind Turbine Systems: Optimization Using Genetic Algorithms," Wind Energy, Vol. 4, No. 4, 2001, pp. 151-171.

[15] A. Arbaoui, “Aide à la Décision Pour la Définition d'un Système Eolien, Adéquation au Site et à un Réseau Faible," Ph.D Thesis of the Ecole Nationale Supérieure d'Arts et Métiers, Bordeaux, 2006.

[16] A. Arbaoui, J. P. Nadeau and P. Sébastian, "Adéquation Site et Système Eolien Eléments d'aide à la Décision par la Modélisation par Contraintes," Revue des Energies Renouvelables, Vol. 8, No. 2, 2005, pp. 81-94.

[17] T. Ackermann, et al., "Embedded Wind Generation in Weak Grids-Economic Optimisation and Power Quality Simulation," Renewable Energy, Vol. 18, No. 2, 1999, pp. 205-221. 


\section{Notation}

A rotor swept area $\left(\mathrm{m}^{2}\right)$,

C Weibull distribution scale parameter $(\mathrm{m} / \mathrm{s})$

$\mathrm{C}_{\text {component }}$ cost of component

$\mathrm{C}_{\mathrm{e}} \quad$ system efficiency factor

$\mathrm{C}_{\mathrm{em}} \quad$ maximum system efficiency factor

$\mathrm{C}_{\mathrm{P}} \quad$ rotor power coefficient

$\mathrm{C}_{\mathrm{pmax}}$

$\mathrm{C}_{\mathrm{X}}$

$\mathrm{C}_{\mathrm{Z}}$

$\mathrm{C}_{\mathrm{WT}}$

D

E annual electricity produced (GWh/year)

$\mathrm{F}_{\mathrm{S}} \quad$ service factor of gearbox

$\mathrm{F}_{\mathrm{WT}} \quad$ cost calibration factor

$\mathrm{F} \quad$ Weibull distribution probability density

$\mathrm{H}_{\text {hub }} \quad$ hub height (m)

$\mathrm{K} \quad$ Weibull distribution shape parameter

$\mathrm{N} \quad$ rotor rotation speed ( $\mathrm{rev} / \mathrm{min}$ )

$\mathrm{P} \quad$ blade number

$\mathrm{P}_{\mathrm{n}} \quad$ nominal power $(\mathrm{kW})$

$\mathrm{P}_{\mathrm{ng}} \quad$ generator power rating $(\mathrm{kW})$
QI quality index

$\mathrm{R}_{\mathrm{r}} \quad$ rotor resistance of the induction generator $(\Omega)$

$\mathrm{R}_{\mathrm{s}} \quad$ stator resistance of the induction generator $(\Omega)$

$\mathrm{S} \quad$ operating range

$\mathrm{V}_{0} \quad$ voltage out put of the induction generator

$\mathrm{V} \quad$ wind speed $(\mathrm{m} / \mathrm{s})$

$\mathrm{V}_{\text {des }} \quad$ design wind speed $(\mathrm{m} / \mathrm{s})$

$\mathrm{V}_{\mathrm{f}} \quad$ network-disconnection speed $(\mathrm{m} / \mathrm{s})$

$\mathrm{V}_{\mathrm{i}} \quad$ network-connection speed $(\mathrm{m} / \mathrm{s})$

$\mathrm{V}_{\mathrm{m}} \quad$ average wind speed at hub height $(\mathrm{m} / \mathrm{s})$

$\mathrm{V}_{\text {tip }} \quad$ blade tip speed $(\mathrm{m} / \mathrm{s})$

$\mathrm{X}_{\mathrm{m}} \quad$ magnetizing reactance $(\Omega)$

$\mathrm{X}_{\mathrm{c}} \quad$ compensating capacitors reactance $(\Omega)$

Greek

$\alpha \quad$ wind shear factor

$\lambda_{\max } \quad$ maximum tip speed ratio

$\rho \quad$ air density $\left(\mathrm{kg} / \mathrm{m}^{3}\right)$

$\eta_{\mathrm{m}} \quad$ gearbox efficiency

$\eta_{\mathrm{g}} \quad$ generator efficiency

$\pi_{\mathrm{g}} \quad$ generator efficiency factor

$\pi_{\mathrm{m}} \quad$ gearbox efficiency factor 